\title{
Sandflies (Diptera: Psychodidae: Phlebotominae) collected on the banks of the Velhas River in the state of Minas Gerais, Brazil
}

\author{
Lara Saraiva, Gustavo Mayr de Lima Carvalho, Cristiani de Castilho Sanguinette, \\ Deborah Aparecida Alves de Carvalho, Alda Lima Falcão, José Dilermando Andrade Filho/ ${ }^{+}$
}

Centro de Referência Nacional e Internacional para Flebotomíneos, Centro de Pesquisas René Rachou-Fiocruz, Av. Augusto de Lima 1715, 30190-002 Belo Horizonte, MG, Brasil

Leishmaniases are endemic to several Brazilian states, including Minas Gerais. As many cases of these diseases are diagnosed in Minas Gerais every year, this paper aimed to determine the diversity of the species of sandflies vector of leishmaniases, in Lassance and Corinto on the banks of the Velhas River. Over two years, 21,014 specimens of sandflies, belonging to 19 species were captured with light traps. Of these specimens, Nyssomyia neivai (Pinto 1926) (84.18\%), Nyssomyia intermedia (Lutz \& Neiva 1912) (13.41\%), Evandromyia lenti (Mangabeira 1938) (0.99\%) and Evandromyia sallesi (Galvão \& Coutinho 1939) (0.48\%) were the most represented. The former two species could be involved in the epidemiological chain of leishmaniasis in this region. No significant difference was found between the species compositions on the two river banks.

Key words: Phlebotominae - leishmaniasis - Velhas River

The principal factor that drives the study of phlebotomine sandflies is their potential role as vectors of Leishmania spp. worldwide. Over 800 species have already been described and it has been estimated that at least 81 of these may be involved in Leishmania transmission (Killick-Kendrick 1990).

Leishmaniases constitute an important public health problem and are endemic to most Brazilian states, in which the sandfly fauna is diverse and widely distributed. As suggested by Andrade Filho et al. (2001) the great adaptability of sandflies to man-made environments favours an increase in the number of cases of leishmaniasis due to the progressive deterioration of natural areas containing the original sandfly habitats.

This study aimed to determine the diversity of the species of sandflies collected with light traps in Lassance and Corinto on the banks of the Velhas River, state of Minas Gerais. The municipalities of Lassance and Corinto are located in the region of Alto São Francisco in the Brazilian state of Minas Gerais. Lassance has an area of $3,214 \mathrm{~km}^{2}$ and 6,554 inhabitants, whereas Corinto has an area of $2,541 \mathrm{~km}^{2}$ and a population of 24,678 . The principal economic activities of the region are agriculture, livestock and fishing. The mean annual temperature is approximately $23^{\circ} \mathrm{C}$ and the predominant vegetation type is cerrado. In the urban and rural areas, between 1986-1999, there were 24 cases of American tegumentary leishmaniasis (ATL) in Lassance and 37 cases in Corinto, as well as one autochthonous case of visceral leishmaniasis (VL) (Secretaria Estadual de

Financial support: CNPq, Fiocruz

+ Corresponding author: jandrade@cpqrr.fiocruz.br

Received 30 June 2008

Accepted 19 November 2008
Saúde). In the following years (2001-2006), seven cases of ATL were recorded in Lassance and five in Corinto, with no cases of VL reported.

Sandfly samples were collected in two consecutive years, from August 2003-July 2005, using modified Falcão light traps (Falcão 1981) that were hung at $18 \mathrm{~h}$ and reviewed at $6 \mathrm{~h}$ the following morning, on two consecutive days of each month. In the second year, due to operational problems, it was not possible to sample the same points as in the first year of sampling or use the same number of traps. In the first year, 16 traps were set, eight in each municipality, equally distributed on opposite banks of the Velhas River. The location of capture 1 was in the Corinto municipality and four traps were hung in the gallery forest on both banks, with an average distance between the points of collections of $370 \mathrm{~m}$. The location of capture 2 was in the Lassance municipality, with one trap hung in a chicken coop, one in a goat pen and two traps hung in the gallery forest on the right bank of the river. On the left side all the ecotopes sampled were the same, but one trap was hung in a corral. The average distance between the points of collections was $240 \mathrm{~m}$. In the second year, 12 traps were set, all in the Lassance municipality, in two distinct areas on opposite sides of the city with three traps on each bank of the river. One of the sites was the same location as collection 2, during the first year. The same ecotopes were sampled but just one trap was placed in the gallery forest for both river banks. The site of collection 3 was located in a northern position in the Lassanse municipality. The average distance between the collection points on the banks was $240 \mathrm{~m}$, with three traps hung in the gallery forest of each bank. The distance between the locations of collection 1 and 2 was $6.9 \mathrm{~km}$ and between the sites of collection 2 and 3 it was $5.8 \mathrm{~km}$.

The collected insects were killed with ether fumes and stored in test tubes containing $70 \%$ alcohol. Speci- 
mens were slide-mounted in Berlese's fluid or Canada balsam and representative specimens were deposited in the Collection of Phlebotomine of Centro de Pesquisas René Rachou-Fiocruz. The classification system used was that of Galati (2003), incorporating the abbreviation scheme for phlebotomine genera proposed by Marcondes (2007). The non-parametric Mann-Whitney test was used, since the samples did not present Gaussian distributions. Data were analyzed using GraphPad Prism 4.

During the survey, we collected 21,015 specimens belonging to 19 species (Table). Of these 19 species, 11 belonged to the sub-tribe Lutzomyiina (Abonnenc \& Leger 1976) and six to Psychodopygina (Galati 1995). Brumptomyiina (Artemiev 1991) and Sergentomyiina (Artemiev 1991) were each represented by one species.

Despite having used a different number of traps, considerably more sandflies were collected in the first year $(17,748)$ than in the second $(3,301)$. The normalised data per sampling effort demonstrated that in the first year the average of the collections was 61.6 specimens/light trap/night. In the second year, the average was 8.5 specimens/light trap/night. The species Psathyromyia brasiliensis (Costa Lima 1932) and Expapillata cerradincola (Galati, Nunes, Oshiro \& Dorval 1995) were collected exclusively in the first and second years, respectively.

The overall male:female (M:F) ratio was 1.05:1. When collections for the two years were analysed separately, the $\mathrm{M}: \mathrm{F}$ ratio was again close to equilibrium (0.97:1) in year one, but males predominated in year two (1.64:1). Males Nyssomyia neivai (Neiva 1926) and Evandromyia lenti (Mangabeira 1938) were predominantly collected, while female Nyssomyia intermedia (Lutz \& Neiva 1912) and Evandromyia sallesi were primarily collected. Only male Lutzomyia longipalpis (Lutz \& Neiva 1912) were collected in two years of captures.

More sandflies were collected on the right bank of the Velhas River (64.13\%), although the species diversity was greater on the left bank, where representatives of all of the species collected in this study were detected. Four species, Pa. brasiliensis, Ex. cerradincola, Pintomyia misionensis (Castro 1939) and Nyssomyia whitmani (Antunes \& Coutinho 1939) were not found on the right bank, although the frequencies of these species on the left bank were low (Table). No significant difference was found between the species compositions on the two river banks $(\mathrm{p}=0.9883)$.

The municipality of Lassance is historically important to science, since it was there that Chagas (1909) discovered the epidemiological aspects of the disease that bears his name. Due to this fact, diverse studies of other diseases were carried out in this municipality at the beginning of the XX century, and Lassance is the type locality for several species of sandflies (Costa Lima 1932). These include Psathyromyia aragaoi (Costa Lima 1932), Brumptomyia nitzulescui (Costa Lima 1932) and Brumptomyia pintoi (Costa Lima 1932), which were all absent in our samples, as well as Brumptomyia brumpti (Larrousse 1920), previously reported by Martins et al. (1978) in Lassance.

According to Forattini (1973), environmental characteristics, such as climate, hydrography, topography, fauna and flora influence the epidemiological patterns of certain diseases. Additionally, Hogue (1993) suggested the importance of physiogeographical conditions for insect populations and the importance of the environment as a determinant of the vertical distribution of certain species of mosquitoes. The differences in the structure of sandflies populations in neighbouring regions separated by geographical barriers has not frequent been frequently studied (Coutinho-Abreu et al. 2008).

Some of the 19 species collected may be involved in Leishmania transmission. Lu. longipalpis is a demonstrated vector of Leishmania infantum chagasi, an aetiologic agent of VL in Brazil (Lainson \& Rangel 2003). It is noteworthy that few specimens of this species were found in the present study, although it is common in the city of Lassance (data not shown). Additionally, $N y$. whitmani is a demonstrated vector of Leishmania braziliensis (Vianna 1911) in various localities (Queiroz et al. 1994, Luz et al. 2000, Carvalho et al. 2008) and Migonemyia migonei (França 1920) may be involved in the transmission of ATL in Brazil (Queiroz et al. 1994, Pita Pereira et al. 2005).

Both $N y$. neivai and $N y$. intermedia are probably involved in the transmission of Le. braziliensis in several regions of Brazil (Pita-Pereira et al. 2005, Andrade Filho et al. 2007). It is important to point out that $N y$. neivai and $E v$. sallesi have been shown to be naturally infected with Le. infantum chagasi (Cunha \& Chagas 1937) in the municipality of Corinto and could be involved in maintenance of the sylvatic cycle of VL in the region (Saraiva et al., unpublished observations). However, this data should be analyzed carefully as the natural infection by one species of Leishmania in one species of sandflies does not conclusively demonstrate that the insect serves as a vector. Currently, many authors are reporting studies of natural infection based on molecular biology techniques, but more detailed studies are needed to determine the role of this natural infection in Leishmania transmission.

Most of the insects were collected on the right bank of the Velhas River, although the species diversity was greater on the opposite side of the river. Although they are superficially similar, the right bank has been modified less by human activities. Several houses on the left bank have animal shelters (chicken coops, corrals and goat pens) that attract various species of sandflies. However, more detailed comparisons of sandfly diversities on the two sides of the river cannot be made since those collected only on the left bank occurred at very low frequencies, except for $N y$. intermedia and $N y$. neivai, which together correspond for $97.6 \%$ of the total collected specimens.

Some authors report variations between sandfly populations in different geographical areas, comparing areas with different degrees of man-made environmental modification. These studies have reported great differences between pastures, orchards, peri and intra-domiciliary environments and primary forest, the last of these having the greatest species diversity (Andrade Filho et al. 2001, De Luca et al. 2003). From this perspective, we could infer that man-made environmental modifications in the study area have reduced sandfly densities, perhaps as a consequence of the incomplete adaptation of the populations to these changes. 


\section{TABLE}

Number and percentual of phlebotomine sandflies collected on the banks of Velhas River in the municipalities of Lassance and Corinto during two years, from August 2003-July 2005

\begin{tabular}{|c|c|c|c|c|c|c|c|c|c|}
\hline \multirow[b]{2}{*}{ Species } & \multicolumn{3}{|c|}{ Year one } & \multicolumn{3}{|c|}{ Year two } & \multicolumn{2}{|c|}{ Banks of Velhas River } & \multirow[b]{2}{*}{ Total } \\
\hline & $\begin{array}{c}\text { Male } \\
\%\end{array}$ & $\begin{array}{c}\text { Female } \\
\%\end{array}$ & Total & $\begin{array}{c}\text { Male } \\
\%\end{array}$ & $\begin{array}{c}\text { Female } \\
\%\end{array}$ & Total & $\begin{array}{l}\text { Left } \\
\text { bank }\end{array}$ & $\begin{array}{l}\text { Right } \\
\text { bank }\end{array}$ & \\
\hline \multirow[t]{2}{*}{ Br. avellari } & 5 & 4 & 9 & 3 & 1 & 4 & 5 & 8 & 13 \\
\hline & 0.02 & 0.02 & 0.03 & 0.01 & 0.00 & 0.01 & 0.02 & 0.04 & 0.06 \\
\hline \multirow[t]{2}{*}{ Pa. brasiliensis } & - & 1 & 1 & - & - & - & 1 & - & 1 \\
\hline & - & 0.00 & 0.00 & - & - & - & 0.00 & - & 0.00 \\
\hline \multirow[t]{2}{*}{ Ex. cerradincola } & - & - & - & - & 1 & 1 & 1 & - & 1 \\
\hline & - & - & - & - & 0.00 & 0.00 & 0.00 & - & 0.00 \\
\hline \multirow{2}{*}{ Ev. evandroi } & 13 & 24 & 37 & 10 & 13 & 23 & 48 & 12 & 60 \\
\hline & 0.06 & 0.11 & 0.18 & 0.04 & 0.06 & 0.11 & 0.23 & 0.06 & 0.29 \\
\hline \multirow{2}{*}{ Ny. intermedia } & 599 & 1439 & 2038 & 392 & 387 & 779 & 964 & 1853 & 2817 \\
\hline & 2.85 & 6.85 & 9.70 & 1.87 & 1.84 & 3.71 & 4.59 & 8.82 & 13.41 \\
\hline \multirow{2}{*}{ Ev. lenti } & 128 & 27 & 155 & 24 & 28 & 52 & 95 & 112 & 207 \\
\hline & 0.61 & 0.13 & 0.74 & 0.11 & 0.13 & 0.25 & 0.45 & 0.53 & 0.99 \\
\hline \multirow{2}{*}{ Lu. longipalpis } & 3 & - & 3 & 6 & - & 6 & 3 & 6 & 9 \\
\hline & 0.01 & - & 0.01 & 0.03 & - & 0.03 & 0.01 & 0.03 & 0.04 \\
\hline \multirow{2}{*}{ Pa. lutziana } & 1 & 1 & 2 & 1 & - & 1 & 1 & 2 & 3 \\
\hline & 0.00 & 0.00 & 0.01 & 0.00 & - & 0.00 & 0.00 & 0.01 & 0.01 \\
\hline \multirow[t]{2}{*}{ Mi. migonei } & - & 1 & 1 & - & 1 & 1 & 1 & 1 & 2 \\
\hline & - & 0.00 & 0.00 & - & 0.00 & 0.00 & 0.00 & 0.00 & 0.01 \\
\hline \multirow[t]{2}{*}{ Pi. misionensis } & - & 1 & 1 & - & 2 & 2 & 3 & - & 3 \\
\hline & - & 0.00 & 0.00 & - & 0.01 & 0.01 & 0.01 & - & 0.01 \\
\hline \multirow{2}{*}{ Ny. neivai } & 7922 & 7442 & 15364 & 1571 & 756 & 2327 & 6319 & 11372 & 17691 \\
\hline & 37.70 & 35.41 & 73.11 & 7.48 & 3.60 & 11.07 & 30.07 & 54.11 & 84.18 \\
\hline \multirow[t]{2}{*}{ Pi.pessoai } & 8 & 4 & 12 & 1 & 1 & 2 & 2 & 12 & 14 \\
\hline & 0.04 & 0.02 & 0.06 & 0.00 & 0.00 & 0.01 & 0.01 & 0.06 & 0.07 \\
\hline \multirow{2}{*}{ Mi. quinquefer } & 9 & 10 & 19 & 2 & 12 & 14 & 26 & 7 & 33 \\
\hline & 0.04 & 0.05 & 0.09 & 0.01 & 0.06 & 0.07 & 0.12 & 0.03 & 0.16 \\
\hline \multirow{2}{*}{ Ev. sallesi } & 24 & 40 & 64 & 12 & 25 & 37 & 39 & 62 & 101 \\
\hline & 0.11 & 0.19 & 0.30 & 0.06 & 0.12 & 0.18 & 0.19 & 0.30 & 0.48 \\
\hline \multirow[t]{2}{*}{ Pa. shannoni } & 2 & - & 2 & - & 1 & 1 & 1 & 2 & 3 \\
\hline & 0.01 & - & 0.01 & - & 0.00 & 0.00 & 0.00 & 0.01 & 0.01 \\
\hline \multirow[t]{2}{*}{ Sc. sordellii } & 1 & 1 & 2 & 1 & 1 & 2 & 2 & 2 & 4 \\
\hline & 0.00 & 0.00 & 0.01 & 0.00 & 0.00 & 0.01 & 0.01 & 0.06 & 0.07 \\
\hline \multirow{2}{*}{ Ev. termitophila } & 5 & 16 & 21 & - & 3 & 3 & 12 & 12 & 24 \\
\hline & 0.02 & 0.08 & 0.10 & - & 0.01 & 0.01 & 0.06 & 0.06 & 0.11 \\
\hline \multirow[t]{2}{*}{ Ev. walkeri } & 8 & 4 & 12 & 7 & 4 & 11 & 8 & 15 & 23 \\
\hline & 0.04 & 0.02 & 0.06 & 0.03 & 0.02 & 0.05 & 0.04 & 0.07 & 0.11 \\
\hline Ny. whitmani & 1 & 2 & 3 & 1 & 2 & 3 & 6 & - & 6 \\
\hline & 0.00 & 0.01 & 0.01 & 0.00 & 0.01 & 0.01 & 0.03 & - & 0.03 \\
\hline Total & 8729 & 9016 & 17746 & 2031 & 1238 & 3269 & 7537 & 13478 & 21015 \\
\hline$\%$ & 1.54 & 42.90 & 84.44 & 9.66 & 5.89 & 15.55 & 35.87 & 64.13 & 100.00 \\
\hline
\end{tabular}

\section{REFERENCES}

Andrade Filho JD, Galati EAB, Falcão AL 2007. Nyssomyia intermedia (Lutz \& Neiva 1912) and Nyssomyia neivai (Pinto 1926) (Diptera: Psychodidae: Phlebotominae) geographical distribution and epidemiological importance. Mem Inst Oswaldo Cruz 102: 481-487.

Andrade Filho JD, Valente MB, Andrade WA, Brazil RP, Falcão AL 2001. Flebotomíneos do Estado de Tocantins, Brasil (Diptera: Psychodidae). Rev Soc Bras Med Trop 34: 323-329.

Carvalho GML, Andrade Filho JD, Falcão AL, Rocha ACVM, Gon- tijo CMF 2008. Naturally infected Lutzomyia sandflies and the transmission of leishmaniasis in an endemic area of Brazil. Vector Borne Zoonotic Dis 8: 407-414.

Chagas C 1909. Nova tripanozomiase humana: estudos sobre a morfolojia e o ciclo evolutivo do Schizotrypanum cruzi n. gen., n. sp., ajente etiolojico de nova entidade mórbida do homem. Mem Inst Oswaldo Cruz 1: 159-218.

Costa Lima A 1932. Sobre os phlebotomos americanos (Diptera: Psychodidae). Mem Inst Oswaldo Cruz 26: 15-59. 
Coutinho-Abreu IV, Sonoda IV, Fonseca JÁ, Melo MA, Balbino VQ, Ramalho-Ortigão M 2008. Lutzomyia longipalpis s.l. in Brazil and the impact of the Sao Francisco River in the speciation of this sandfly vector. Parasit Vectors 1: 1-16.

De Luca AS, Vasconcelos HL, Barrett TV 2003. Distribution of sandlies (Diptera: Phlebotominae) in forest remnants and adjacent matrix habitats in Bazilian Amazonia. Braz J Biol 63: 401-410.

Falcão AR 1981. Um novo modelo de armadilha luminosa de sucção para pequenos insetos. Mem Inst Oswaldo Cruz 76: 303-305.

Forattini OP 1973. Entomologia Médica. Psychodidae, Phlebotominae, Leishmaniose, Bartonelose, Vol. IV, Edgard Blucher, São Paulo, 658 pp.

Galati EAB 2003. Classificação de Phlebotominae. In EF Rangel \& R Lainson, Flebotomíneos do Brasil. Editora Fiocruz, Rio de Janeiro, p. 23-51.

Hogue CL 1993. Latin America Insects and Entomology. University of California Press, Los Angeles, 536 pp.

Killick-Kendrick R 1990. Phlebotomine vectors of the leishmaniasis: a review. Med Vet Entomol 4: 1-24.

Lainson R, Rangel EF 2003. Ecologia das Leishmanioses. In EF Rangel \& R Lainson, Flebotomíneos do Brasil, Editora Fiocruz, Rio de Janeiro, p. 291-309.
Luz E, Castro MEA, Dereure J, Pratlong F, Dedet JA, Pandey A, Soccol VT 2000. Lutzomyia whitmani (Diptera: Psychodidade) as vector of Leishmania (V.) braziliensis in Paraná state, Southern Brazil. Ann Trop Med Parasitol 94: 623-631.

Marcondes CB 2007. A proposal of generic and subgeneric abbreviations for phlebotomine sandflies (Diptera: Psychodidae: Phlebotominae) of the world. Entomol News 118: 351-356.

Martins AV, Williams P, Falcão AL 1978. American Sandflies (Diptera, Psychodidae, Phlebotominae). Academia Brasileira de Ciência, Rio de Janeiro, 195 pp.

Pita-Pereira D, Alves CR, Souza MB, Brazil RP, Bertho AL, de Figueiredo Barbosa A, Britto CC 2005. Identification of naturally infected Lutzomyia intermedia and Lutzomyia migonei with Leishmania (Viannia) braziliensis in Rio de Janeiro (Brazil) revealed by a PCR multiplex non-isotopic hybridisation assay. Trans R Soc Trop Med Hyg 99: 905-913.

Queiroz RG, Vasconcelos IAB, Vasconcelos AW, Pessoa FAC, Souza RN, David JR 1994. Cutaneous leishmaniasis in Ceará state in Northeastern Brazil: incrimination of Lutzomyia whitmani (Diptera: Psychodidae) as a vector of Leishmania braziliensis in Baturite municipality. Am J Trop Med Hyg 50: 693-698. 